\title{
The study on the effect of voltage ripple on multiphase buck converters with phase shedding control scheme for SCADA applications
}

\author{
Mini P. Varghese ${ }^{1}$, A. Manjunatha ${ }^{2}$, T. V. Snehaprabha ${ }^{3}$ \\ ${ }^{1,2}$ Department of Electrical and Electronics Engineering, Sri Krishna Institute of Technology, Bangalore, India \\ ${ }^{3}$ Department of Electrical and Electronics Engineering, Presidency University, Bangalore, India
}

\begin{tabular}{l} 
Article Info \\
\hline Article history: \\
Received Jan 11, 2021 \\
Revised Apr 13, 2021 \\
Accepted Jun 14, 2021 \\
\hline Keywords: \\
Multiphase buck converter \\
Phase shedding \\
Ripple cancellation \\
Steady state analysis \\
Voltage regulator module
\end{tabular}

\begin{abstract}
Voltage regulator modules (VRM) need to have low output voltage ripple and tight efficiency to power advanced microprocessors. This paper explains a phase shedding technique to enhance efficiency and its impact on output voltage ripple. In this study, analysis was done on a 4-phase buck converter which is having an input voltage of $45-65 \mathrm{~V}$ and delivers an output of $9 \mathrm{~V}$, $12 \mathrm{~A}$ with a switching frequency of $200 \mathrm{Khz}$. The phase shedding control scheme is suitable for applications such as power sources for programmable logic controllers, which is a part of SCADA systems, which requires a low voltage and high current power supply. Working of a multiphase buck converter with phase shedding is modelled and verified using Matlab/Simulink software. The simulation results show the effect of the phase shedding technique on efficiency in varying load conditions and the effect of an increase of the voltage ripple at the output.
\end{abstract}

This is an open access article under the CC BY-SA license.

\section{Corresponding Author:}

Mini P. Varghese

Department of Electrical and Electronics Engineering

Sri Krishna Institute of Technology

Bangalore-560090, Karnataka, India

Email: mini.jinan@gmail.com

\section{INTRODUCTION}

Datacenter power consumption has increased considerably as a result of the widespread adoption of cloud computing. Datacenters such as supervisory control and data acquisition (SCADA) systems, typically use a large number of central processing units (CPU), that necessitates a well-regulated DC voltage, as well as adherence to exceedingly stringent regulations and specifications [1]. As the demand for processing from processors increases, the needed output current of converters for computing devices continues to grow as well. The multi-phase interleaved buck converter is widely used to deliver more output current with lower output voltage ripple [2]. For low voltage and high current applications, a multi-phase buck converter is recommended because it minimizes current stress in each phase while also reducing output capacitor size due to ripple cancellation [3]. Due to its wide load range operation, fast dynamic response, superior light-load efficiency, and smaller output ripple, this type of converter is also employed in high slew rate load powering [4]. At light loads, some converters with high current ratings have low efficiency [5]. Because of this, efficiency became a major factor in multiphase converters. However, in reality, the voltage regulator modules do not always operate at maximum power. As a result, efficiency at light and medium loads drops [6], [7]. Voltage converters and regulators with high efficiency and low cost are key components in most low-power design techniques [8]. 
Multiphase buck converter has a drawback in terms of maintaining higher efficiency during light and heavy load. Some studies have shown that effciency reduces to a minimum during light load. To improve light-load efficiency, we have employed phase shedding technique by turning off phases during load change, especially in the case of light loads. Phase shedding technique works such that the number of operating phases in a multiphase converter decreases when the load current reduces, and during a light-load state, a single-phase will gradually be connected to the load system [9]. By activating the necessary number of stages at any given load, improved light load efficiencies can be attained utilizing phase shedding techniques [10]. The suggested converter uses a load-dependent control method that combines PWM control with phaseshedding for loads in a wide range to improve efficiency at lighter loads [11]. In this way, efficiency can be improved during reduced (light) load. Phase shedding negatively affects the advantage of using a multiphase buck converter such as its ripple cancellation technique. In general, for low-voltage loads phase shedding technique works well but at the same time, ripple voltage at the output will increase. As a result, the advantage of using the phase shedding technique will no longer be effective. This paper presents the original simulated results which prove that there is an increase in the ripple voltage during load change.

SCADA are computer based control systems that are used to control processes at industrial organizations. These industrial processes will be controlled at remote locations or locally. SCADA networks are also used to collect data from the field, send it to a central computer facility, and display it graphically or textually for users. As a result, users may monitor or operate an entire network in real time from a remote place [12]. SCADA server is responsible for the communication with the remote terminal units, programmable logic controllers (PLC), etc. PLC use high power processors which require power supplies with high efficiency at any power level and ripple-free supply. The proposed phase shedding technique for a multiphase buck converter [13] is applicable for these kinds of power supplies where it needs a very low ripple and highly efficient supply. At medium and low loads, however, disabling a few numbers of modules (or phases) results in an increase in the amplitudes of the input and output current ripples [14]-[16]. Approaches like this can increase noise at the output as a factor of voltage ripple and current ripple requirements specified in PLC processor power supplies. The proposed voltage regulator which is tested with different loads [17] serves the requirements of these high-end processors that are used in SCADA systems.

A multiphase converter using the phase shedding technique is discussed in this paper. The following is a breakdown of the paper's structure. Section 2 explains parameters that need to be taken care of while designing converter circuit. Efficiency as per different load conditions is compared in the section 3. Section 4 describes simulation results that validate the effect of phase shedding on ripple voltage and the work is concluded in the section 5 .

\section{DESIGN CONSIDERATIONS IN MULTIPHASE BUCK CONVERTERS}

\subsection{Effect of losses on efficiency}

Converter losses are generally divided into two main groups such as fixed losses and load-dependent losses. The losses in the multiphase converters can be expressed as the total of switching losses which is considered as fixed losses and conduction losses, which is considered load dependent losses. Switching loss in a single-phase converter will be very less because of the lesser number of switching elements. But in the case of multiphase converters, switching losses are high due to a greater number of stages. The conduction losses mainly depend on the current through the elements present in each phase. Also, switching losses are directly proportional to the switching frequency. As a result, because phase shedding is frequency-dependent, losses will increase considerably as the number of phases rises. This affects overall multiphase converter efficiency. The failure to achieve high efficiency across the whole load range is due to the fact that all phases are kept similar in terms of inductor size, switching frequency, and load sharing [18]. The conduction losses and switching losses can be calculated using:

$$
\begin{aligned}
& \mathrm{P}=\mathrm{Rds} . \mathrm{Idc}^{2} \\
& \mathrm{Psw}=[\text { Vin.Isw.fsw }(\mathrm{tr}+\mathrm{tf})] / 2
\end{aligned}
$$

\subsection{Ripple voltage at the output}

Connecting and disconnecting a number of phases not only changes the efficiency but also affect the output voltage ripple in a negative way [12]. Because the phase-shift among the phases changes as the number of active phases varies with the output load, the ripple cancellation effect generated by multiphase is decreased [14]-[16]. This is a major drawback and will affect the converter with an increase in noise. Some concepts about multiphase must be considered while describing the influence of output voltage ripple. The amount of output voltage ripples is a major concern in switching regulators since they affect converter performance. The charging and discharging of the equivalent output capacitor constitute the majority of the

The study on the effect of voltage ripple on multiphase buck converters with phase ... (Mini P. Varghese) 
output voltage ripple amplitude. The ripple's volume is defined by the load current, total output capacitor, switching frequency, and number of phases supplied to the system [2]. In (3) describes the relation between output voltage ripple, output capacitance and switching frequency and how these parameters are utilised to reduce output voltage ripple. When switching frequency is reduced due to phase shedding during a light load state, output voltage ripple is dramatically increased. The increase in the capacitor value can reduce the output voltage ripple during the charge- discharge cycle. But this will increase the physical size of the capacitor and hence overall voltage regulator module dimension will increase. In order to reduce the size of the output filter capacitor, most voltage regulators require high-frequency operation [19].

$\Delta \mathrm{V}=\mathrm{IL} /[2$. Cout.fsw.N]

\subsection{Design specification}

A four-phase buck converter circuit with the following parameters [20] is simulated according to the specification presented in Table 1. Analysis is done based on this design specification [21].

Table 1. Design specifications

\begin{tabular}{lc}
\hline \multicolumn{1}{c}{ Parameters } & Nominal value \\
\hline Input voltage & $(45-65) \mathrm{V}$ \\
Output voltage & $9 \mathrm{~V}$ \\
Output current & $12 \mathrm{~A}$ \\
DC regulation & $<1.2 \%$ \\
Switching frequency & $200 \mathrm{KHz}$ \\
Output voltage ripple & $90 \mathrm{mV}$ \\
\hline
\end{tabular}

\section{COMPARISON OF EFFICIENCY AS PER LOAD DEMAND}

Results obtained from simulation and calculation of efficiency shows that there is a rise in light load efficiency after implementing the phase shedding technique in a multiphase converter. During light load after turning off all the other phases as per the load demand shows that this technique is very useful when there is a demand for high efficiency. The operational phase number is determined by the output current in the traditional approach of phase-shedding control. At low output currents, a few phases are used while converting to a single phase to reduce switching losses caused by the converter's active switch devices. As the load current increases, conduction losses begin to exceed switching losses. As a result, more phases are activated or deactivated in order to maintain maximum efficiency [14], [22], [23].

Tables 2-5 show the variation of output current and efficiency. As the load decreases, efficiency also decreases and this is compensated with the reduction in the number of phases with the phase shedding technique. The transition from one phase to another as per load demand can be achieved by pre-setting a threshold value of load current. Table 2 shows the efficiency versus load current in multiphase converters without phase shedding, which is taken as stage1, where all the 4 phases are in ON state. Light load efficiency in this stage is $87.67 \%$. Table 3 shows the efficiency versus load current in multiphase converters with phase shedding, which is taken as stage2, where 3 phases are in ON state. Light load efficiency in this stage is $88.04 \%$. Table 4 shows the efficiency versus load current in multiphase converters with phase shedding, which is taken as stage 3 , where 2 phases are in ON state. Light load efficiency in this stage is $89.68 \%$. Table 5 shows the efficiency versus load current in multiphase converters with phase shedding, which is taken as stage4, where only one phase is in ON state. Light load efficiency is improved to $90.91 \%$.

Table 2. o/p current and efficiency from Stage1

\begin{tabular}{cccc}
\hline Iout & Pout & Pin & Efficiency \\
\hline 1 & 9 & 10.26 & 87.67 \\
2 & 18 & 19.72 & 91.23 \\
3 & 27 & 29.20 & 92.45 \\
4 & 36 & 38.68 & 93.05 \\
5 & 45 & 48.17 & 93.40 \\
6 & 54 & 57.67 & 93.62 \\
7 & 63 & 67.19 & 93.76 \\
8 & 72 & 76.71 & 93.85 \\
9 & 81 & 86.24 & 93.92 \\
10 & 90 & 95.78 & 93.96 \\
11 & 99 & 105.32 & 93.99 \\
12 & 108 & 114.88 & 94.05 \\
\hline
\end{tabular}

Table 3. o/p current and efficiency from Stage 2

\begin{tabular}{cccc}
\hline Iout & Pout & Pin & Efficiency \\
\hline 1 & 9 & 10.22 & 88.04 \\
2 & 18 & 19.75 & 91.09 \\
3 & 27 & 29.30 & 92.12 \\
4 & 36 & 38.86 & 92.61 \\
5 & 45 & 48.44 & 92.89 \\
6 & 54 & 58.02 & 93.05 \\
7 & 63 & 67.62 & 93.15 \\
8 & 72 & 77.23 & 93.21 \\
9 & 81 & 86.86 & 93.24 \\
10 & 90 & 96.50 & 93.26 \\
11 & 99 & 106.14 & 93.26 \\
12 & 108 & 115.81 & 93.25 \\
\hline
\end{tabular}


Table 4. o/p current and efficiency from Stage3

\begin{tabular}{cccc}
\hline Iout & Pout & Pin & Efficiency \\
\hline 1 & 9 & 10.03 & 89.68 \\
2 & 18 & 19.60 & 91.81 \\
3 & 27 & 29.19 & 92.49 \\
4 & 36 & 38.79 & 92.79 \\
5 & 45 & 48.42 & 92.93 \\
6 & 54 & 58.06 & 93.00 \\
7 & 63 & 67.72 & 93.02 \\
8 & 72 & 77.40 & 93.01 \\
9 & 81 & 87.10 & 92.98 \\
10 & 90 & 96.82 & 92.95 \\
11 & 99 & 106.56 & 92.90 \\
12 & 108 & 116.31 & 92.84 \\
\hline
\end{tabular}

Table 5. o/p current and efficiency from Stage4

\begin{tabular}{cccc}
\hline Iout & Pout & Pin & Efficiency \\
\hline 1 & 9 & 9.89 & 90.91 \\
2 & 18 & 19.56 & 92.00 \\
3 & 27 & 29.26 & 92.26 \\
4 & 36 & 39.00 & 92.29 \\
5 & 45 & 48.78 & 92.24 \\
6 & 54 & 58.59 & 92.15 \\
7 & 63 & 68.44 & 92.04 \\
8 & 72 & 78.33 & 91.91 \\
9 & 81 & 88.26 & 91.77 \\
10 & 90 & 98.22 & 91.62 \\
11 & 99 & 108.23 & 91.47 \\
12 & 108 & 118.27 & 91.31 \\
\hline
\end{tabular}

Figure 1 shows the efficiency curve obtained for different values of load current. In this graph, efficiency for all 4 phases plotted as per the calculated values. So it is proven from these results that light load efficiency for the multiphase phase voltage regulator is improved [24].

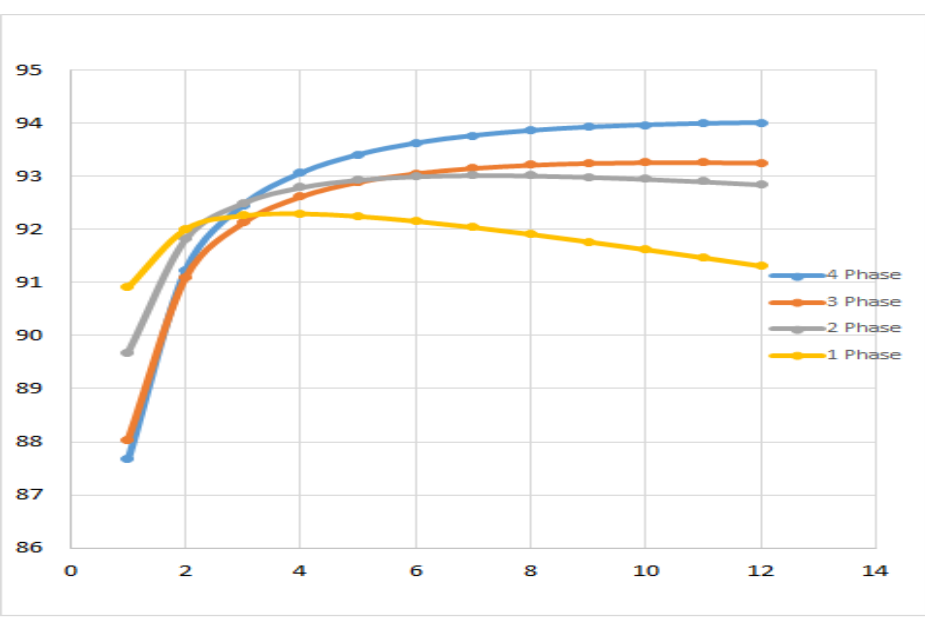

Load current $\rightarrow$

Figure.1. Efficiency versus load current

\section{SIMULATION RESULTS}

Figure 2 illustrates the Simulink model of the proposed four-stage multiphase buck converter with phase shedding methodology, which was simulated in Matlab/Simulink [25]. Each one of the four buck converter stages in the model has its own inductor, diode, and power MOSFET. These elements are referred to as a phase when combined together. By simulating different load levels and phase shifts in its steady state condition, the suggested model was used to investigate the effect of output voltage ripple. Individual phases are active at spaced intervals equal to $360^{\circ} / \mathrm{n}$ throughout the switching period in steady-state operation, where $\mathrm{n}$ is the total number of phases. The multiphase converter is simulated with a load of $12 \mathrm{~A}$ when all the 4phases of it is in the ON state and simulated with a light load of $3 \mathrm{~A}$ when the only single phase of it is in the $\mathrm{ON}$ state. Figure 3 shows gate pulses to the 4 stages of the multiphase buck converter. Figure 4 shows ripple voltage $(.4 \mathrm{mV})$ and output current $(12 \mathrm{~A})$. Figure 5 shows output current at $12 \mathrm{~A}$ and output voltage regulated at $9 \mathrm{~V}$. Figure 6 shows gate pulses to the 3 stages of the multiphase buck converter. Figure 7 shows ripple voltage $(2.5 \mathrm{mV})$ and output current $(9 \mathrm{~A})$ after shedding one phase as per load requirement. Figure 8 shows gate pulses to the 2 stages of the multiphase buck converter. Figure 9 shows ripple voltage $(3 \mathrm{mV})$ and output current (9A) after shedding 2 phases as per load demand. Figure 10 shows gate pulses to the one stage of the multiphase buck converter. During this instant, switch in all the other 3 phases will be in OFF state. Required output current will be through this single stage. Since output current demand is less, power dissipation in the single-stage will also become negligible. This directly helps to improve the overall efficiency and performance of the system. Figure 11 shows ripple voltage $(3.5 \mathrm{mV})$ and output current $(3 \mathrm{~A})$ after shedding 3 phases as per load demand. 

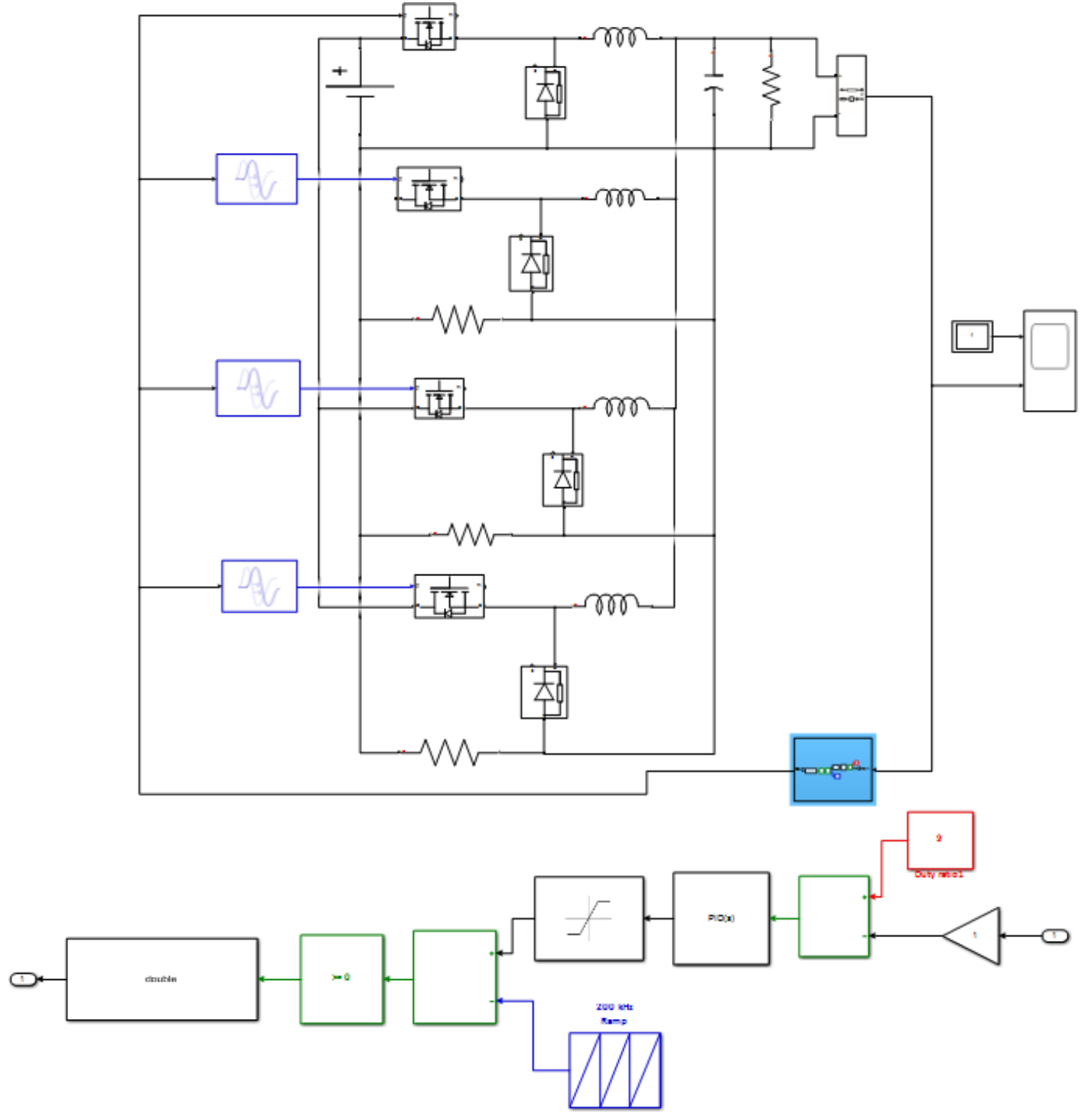

Figure 2. Simulink block diagram of 4stage buck converter
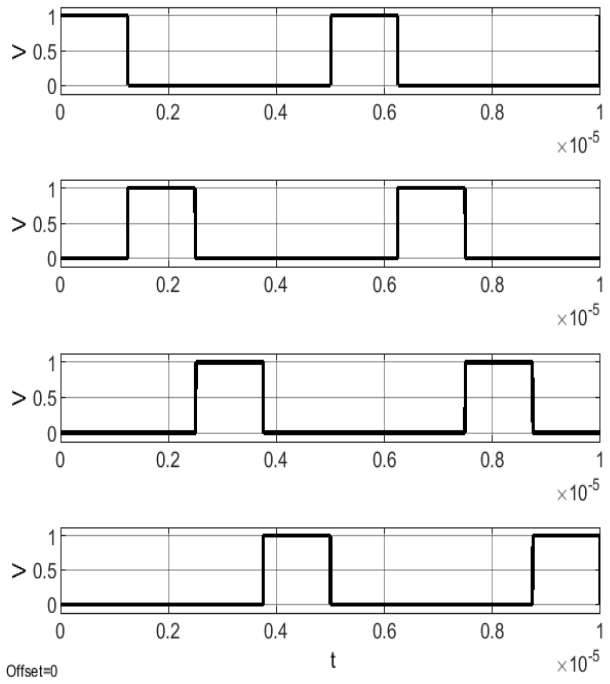

Figure 3. Gate pulses for 4stages of converter
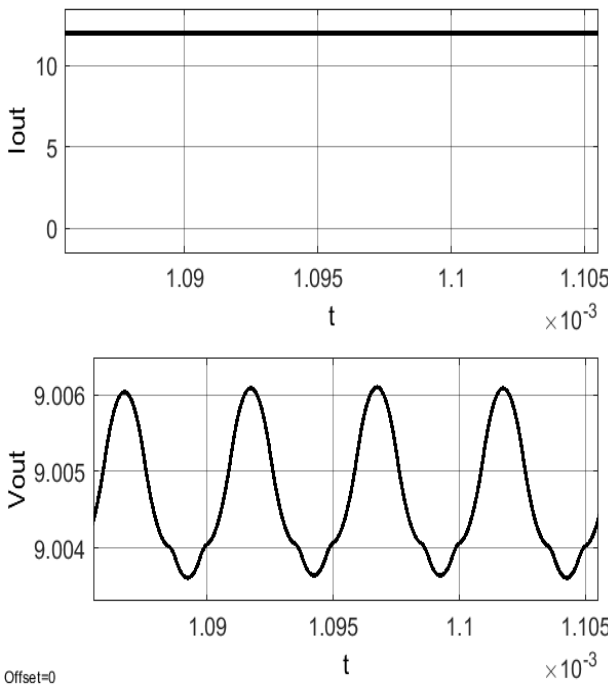

Figure 4. Output current and output ripple (4phase) 

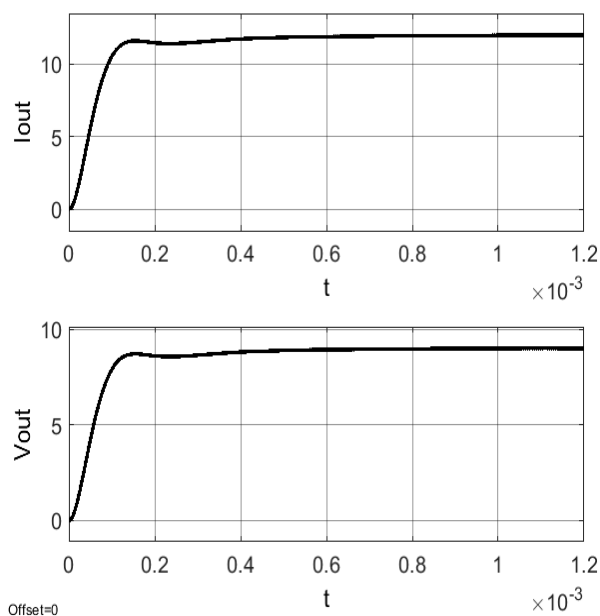

Figure 5. Voltage and current at the output
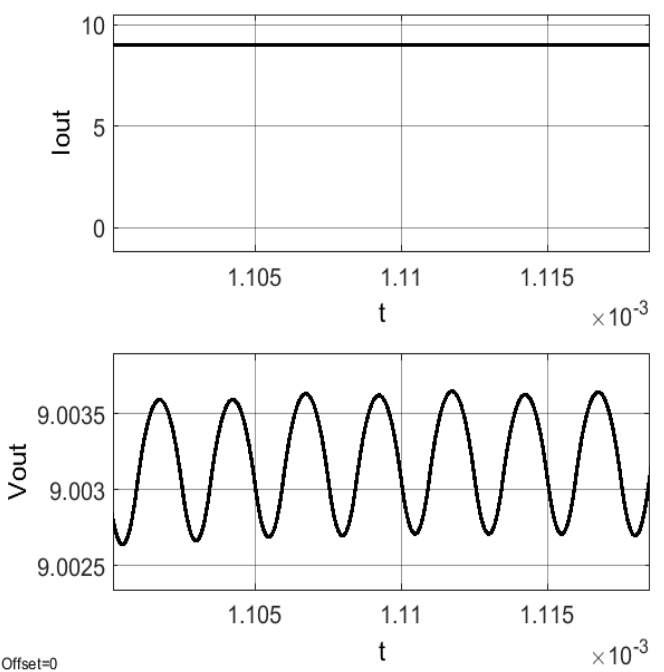

Figure 7. Output current and output ripple voltage (3 phase)
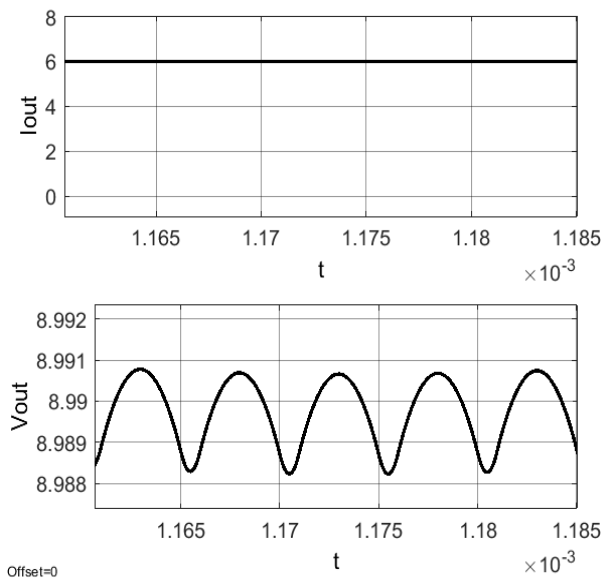

Figure 9. Output current and output ripple voltage (2 phase)
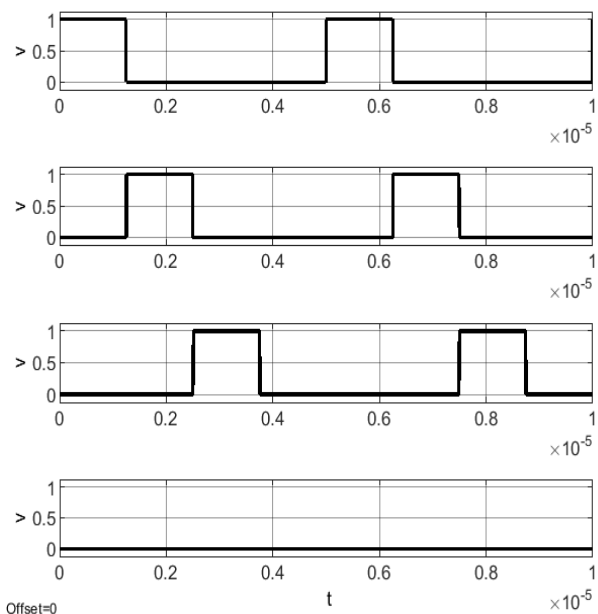

Figure 6. Gate pulses for 3stages of converter
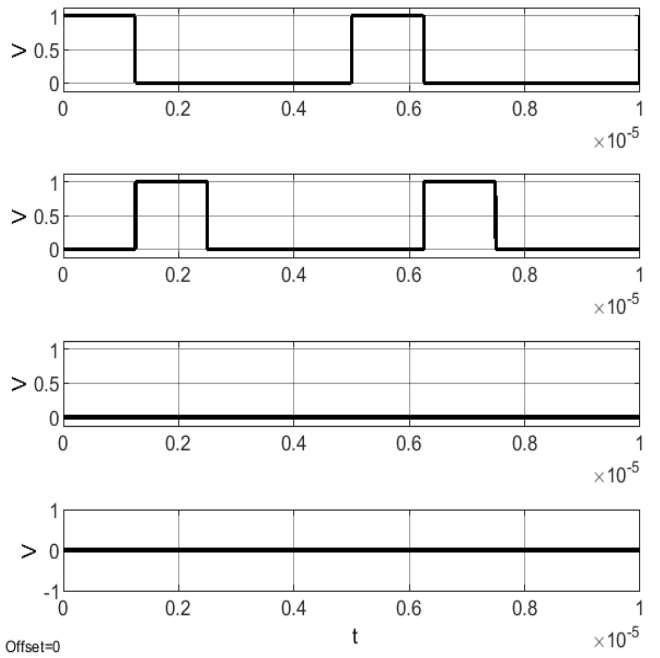

Figure 8. Gate pulses for 2stages of converter
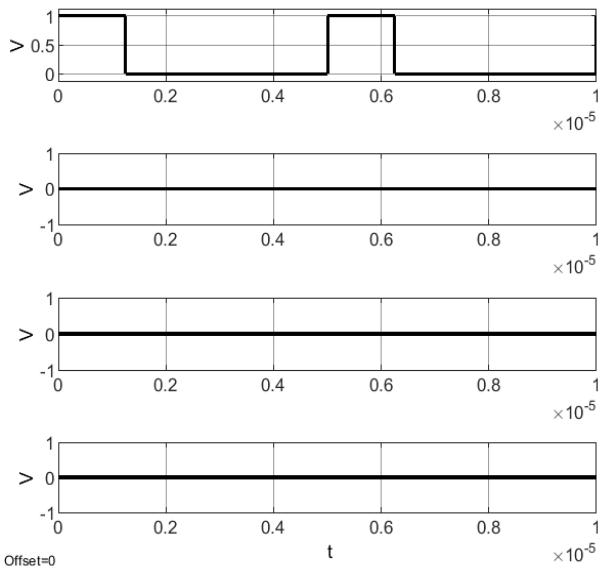

Figure 10. Gate pulses for single stage converter 

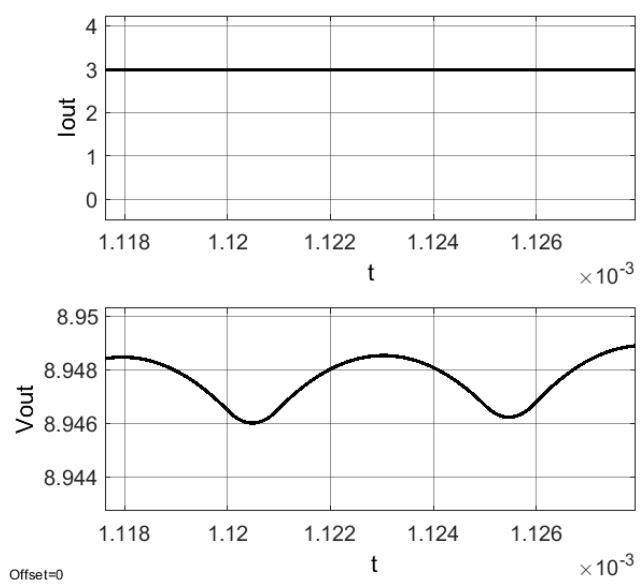

Figure 11. Waveforms of output current and output ripple voltage (1 phase)

\section{CONCLUSION}

This study discusses the performance of a multiphase converter using a phase shedding control system. With the help of simulation study using MATLAB, improvement in efficiency and effect of output voltage ripple in multiphase converter with phase shedding is verified. When the number of stages is reduced as per load requirement, it has improved light-load efficiency and increment in the output voltage ripple. We have simulated the converter without phase shedding and obtained a light load efficiency of $87.67 \%$, output voltage ripple of $0.4 \mathrm{mV}$. Later, the same condition is simulated again by implementing the phase shedding technique and turned ON only a single phase. During this condition we have obtained an efficiency of $90.91 \%$ and an output voltage ripple of $3.5 \mathrm{mV}$. These results prove the improvement in efficiency and effect of ripple voltage at the output as per load change. Also, this study has presented the effect of various parameters which might be a reason for the increment of the output voltage ripple.

\section{REFERENCES}

[1] B. Halivni and M. M. Peretz, "Digital Controller for High-Performance Multiphase VRM with Current Balancing and Near-Ideal Transient Response," 2020 IEEE Applied Power Electronics Conference and Exposition (APEC), 2020, pp. 2206-2213, doi: 10.1109/APEC39645.2020.9124261.

[2] C. -J. Chen, Z. -Y. Zeng, C. -H. Cheng and F. -T. Lin, "Comprehensive Analysis and Design of Current-Balance Loop in Constant On-Time Controlled Multi-Phase Buck Converter," in IEEE Access, vol. 8, pp. 184752-184764, 2020, doi: 10.1109/ACCESS.2020.3029069.

[3] A. Acharya, V. I. Kumar and S. Kapat, "Dynamic Bus Voltage Reconfiguration in a Two-Stage Multiphase Converter for Fast Transient," in IEEE Journal of Emerging and Selected Topics in Power Electronics, vol. 9, no. 1, pp. 48-57, Feb. 2021, doi: 10.1109/JESTPE.2020.2971710.

[4] C. Hong, C. Tsai and C. Chen, "A Gm-Ramped Interleaving Technique with Adaptive-Extended TON Control (AETC) Scheme for Multi-phase Buck Converter Achieving Fast Load Response," 2020 IEEE Applied Power Electronics Conference and Exposition (APEC), 2020, pp. 326-331, doi: 10.1109/APEC39645.2020.9124124.

[5] J. Lee, C. Huang, T. Liang and K. Chen, "Design of control IC for multiphase interleaved buck converter with alternate phase-shedding," 2015 9th International Conference on Power Electronics and ECCE Asia (ICPE-ECCE Asia), 2015, pp. 1025-1032, doi: 10.1109/ICPE.2015.7167907.

[6] W.Y. Wang, H.H.C. Iu, W. Du, V. Sreeram, "Multiphase dc-dc converter with high dynamic performance and high efficiency," IET power electronics, vol. 4, no. 1, pp. 101-110, Jan 2011, doi: 10.1049/iet-pel.2009.0215.

[7] Xunwei Zhou, M. Donati, L. Amoroso and F. C. Lee, "Improved light-load efficiency for synchronous rectifier voltage regulator module," in IEEE Transactions on Power Electronics, vol. 15, no. 5, pp. 826-834, Sept. 2000, doi: $10.1109 / 63.867671$.

[8] C. Yan, Z. Gan and E. Salman, "In-package spiral inductor characterization for high efficiency buck converters," 2017 IEEE International Symposium on Circuits and Systems (ISCAS), 2017, pp. 1-4, doi: 10.1109/ISCAS.2017.8050892.

[9] Y. Ahn, I. Jeon and J. Roh, "A Multiphase Buck Converter With a Rotating Phase-Shedding Scheme For Efficient Light-Load Control," in IEEE Journal of Solid-State Circuits, vol. 49, no. 11, pp. 2673-2683, Nov. 2014, doi: 10.1109/JSSC.2014.2360400.

[10] S. M. Shiva, N. B. Y. Gorla, P. Das and S. K. Panda, "A new phase shedding and phase adding control scheme for interleaved DAB converter operating in IPOP configuration," 2015 IEEE International Telecommunications Energy Conference (INTELEC), 2015, pp. 1-6, doi: 10.1109/INTLEC.2015.7572420. 
[11] M. Singh and A. Fayed, "An 8 A 100-MHz 4-Phase Buck Converter with Fast Dynamic Response and Enhanced Light-Load Efficiency," 2018 IEEE 61st International Midwest Symposium on Circuits and Systems (MWSCAS), 2018, pp. 861-864, doi: 10.1109/MWSCAS.2018.8623899.

[12] A. Rezaia, P. Keshavarzi, and Z. Moravej, "Key management issue in SCADA networks: A review," Engineering science and technology, an international journal, vol. 20, no. 1, pp. 354-363, 2017, Feb. 2017.

[13] G. Zhu, L. Mu, and J. Yan, "A Novel Multi-Function PV Micro-Inverter with an Optimized Harmonic Compensation Strategy," Journal of Power Electronics, vol. 16, no. 6, pp. 2284-2293, Nov. 2016, doi: 10.6113/JPE.2016.16.6.2284

[14] M. A. Alharbi, M. Dahidah, S. Ali, S. Ethni and V. Pickert, "Current Ripple Minimisation Based on PhaseShedding of DC-DC Interleaved Converters for EV Charging System," IECON 2019 - 45th Annual Conference of the IEEE Industrial Electronics Society, 2019, pp. 3456-3462, doi: 10.1109/IECON.2019.8926959.

[15] P. Zumel, C. Fernández, A. de Castro and O. García, "Efficiency improvement in multiphase converter by changing dynamically the number of phases," 2006 37th IEEE Power Electronics Specialists Conference, 2006, pp. 1-6, doi: 10.1109/pesc.2006.1712202.

[16] Chuanyun Wang, Ming Xu, F. C. Lee and Zheng Luo, "Light load efficiency improvement for multi-channel PFC," 2008 IEEE Power Electronics Specialists Conference, 2008, pp. 4080-4085, doi: 10.1109/PESC.2008.4592592.

[17] M. A. Hutabarat, S. Hasan, A. H. Rambe, S. Suherman, "Design and simulation hybrid filter for 17 level multilevel inverter," Bulletin of Electrical Engineering and Informatics, vol. 9, no. 3, pp. 886-897, Jun 2020, doi: 10.11591/eei.v9i3.890.

[18] M. Singh and A. Fayed, "Imbalanced High-Current Multi-Phase Buck Converters for High-Performance CPUs," 2019 IEEE 62nd International Midwest Symposium on Circuits and Systems (MWSCAS), 2019, pp. 929-932, doi: 10.1109/MWSCAS.2019.8885141.

[19] N. Narasimman, R. Salahuddin and R. P. Singh, "An 86\% efficiency Multi-Phase Buck Converter using TimeDomain Compensator and Adaptive Dead-Time Control for DVS Application," IECON 2020 The 46th Annual Conference of the IEEE Industrial Electronics Society, 2020, pp. 2255-2260, doi: 10.1109/IECON43393.2020.9255080.

[20] Liyu Yang, Jiwei Fan and A. Q. Huang, "Controller design issues and solutions for buck converters with phase shedding and AVP functions," 2009 IEEE Energy Conversion Congress and Exposition, 2009, pp. 2862-2868, doi: 10.1109/ECCE.2009.5316266.

[21] Seung-Ho Baek, Soon-Ryung Lee and Chung-Yuen Won, "A novel phase shedding control algorithm considering maximum efficiency for 3-phase interleaved boost converter," 2016 IEEE Transportation Electrification Conference and Expo, Asia-Pacific (ITEC Asia-Pacific), 2016, pp. 427-431, doi: 10.1109/ITEC-AP.2016.7512991.

[22] J. Su and C. Liu, "A Novel Phase-Shedding Control Scheme for Improved Light Load Efficiency of Multiphase Interleaved DC-DC Converters," in IEEE Transactions on Power Electronics, vol. 28, no. 10, pp. 4742-4752, Oct. 2013, doi: 10.1109/TPEL.2012.2233220.

[23] L. Fleischli, S. Lemofouet and A. Rufer, "Multichannel DC-DC Converter's Efficiency Optimisation by variable Number of active Channels," IECON 2006 - 32nd Annual Conference on IEEE Industrial Electronics, 2006, pp. 2581-2586, doi: 10.1109/IECON.2006.347253.

[24] C. Fei, M. H. Ahmed, F. C. Lee and Q. Li, "Dynamic bus voltage control for light load efficiency improvement of two-stage voltage regulator," 2016 IEEE Energy Conversion Congress and Exposition (ECCE), 2016, pp. 1-8, doi: 10.1109/ECCE.2016.7855057.

[25] C. R. Balamurugan, K. Vijayalakshmi, "Comparative analysis of various z-source based five level cascaded Hbridge multilevel inverter," Bulletin of Electrical Engineering and Informatics, vol. 7, no. 1, pp. 1-4, Mar 2018, doi: 10.11591/eei.v7i1.656. 